\title{
Production of a map of greenhouse gas emissions and energy use from Australian agriculture
}

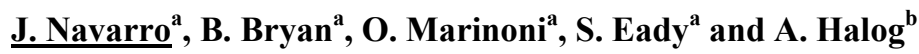 \\ ${ }^{a}$ Commonwealth Scientific and Industrial Research Corporation (CSIRO) - Sustainable Agriculture \\ Flagship and Ecosystem Sciences \\ ${ }^{b}$ The University of Queensland - School of Geography, Planning and Environmental Management \\ Email:javi.navarro@csiro.au
}

\begin{abstract}
The agriculture and forestry sector accounts for approximately $24 \%$ of total greenhouse gas (GHG) emissions in Australia. Over the years researchers have produced new knowledge about agricultural GHG emissions and energy use patterns and opportunities to decrease them, albeit in small-scale studies or large-scale ones with coarse resolution. Linking the multiple, diverse and rich datasets around agricultural production in Australia into one dataset that allows for an estimate of GHG emissions and energy use related to agriculture at a national scale and high resolution has not been done before.
\end{abstract}

The approach we describe here is based upon a link between operational data sourced from gross margin (GM) handbooks and life cycle assessment (LCA) process data. We have collected and processed these datasets to produce a comprehensive database of typical agricultural operations covering 72 commodities grown in 42 regions across Australia. We have also created a system that estimates the GHG emission and energy use patterns of the aforementioned commodities using the best available LCA process data.

To capture GHG emissions of non-domestically produced fertiliser, we queried the United Nations Commodity Trade Statistics Database (COMTRADE) to analyse the fertiliser and pesticide import patterns for Australia between 2000-2010. This analysis determined the average country energy-mix for fertiliser and pesticide manufacturing and allowed linking the associated GHG emissions to Australian agricultural production.

Finally we spatialised agricultural operational data, emissions and energy use at the national scale using the latest Australian Land Use Map (2005/06). Our findings suggest that in 2005/06 greenhouse gas emissions related to Australian agricultural production equate to a total of $95.8 \mathrm{Mt} \mathrm{CO}_{2}$-e using $75.7 \mathrm{GWh}$ of energy. According to our results $29.4 \%$ of these emissions come from sources that were categorised as nonagricultural (e.g. industrial processes or energy use) in the Australian National Greenhouse Gas Inventory (NGGI) 2006. We find that the provision of transparently modeled GHG emissions and having them linked to a spatially explicit component helps identifying new opportunities for emission reduction and facilitates an assessment of their effects. For example, our findings suggest production of ethanol from corn stover and sugarcane bagasse could have avoided 4.37 $\mathrm{Mt} \mathrm{CO}_{2}$-e emissions (4.56\% of total) without affecting food production.

Keywords: $\quad$ Agricultural Systems, GHG Emissions, Energy Use, LCA, GIS 


\section{INTRODUCTION}

The agriculture and forestry sector accounts for approximately $24 \%$ of total greenhouse gas (GHG) emissions in Australia (AGEIS, 2013) The increased cost of farm inputs (such as diesel, electricity and fertilisers) is a driver for reduction of GHG emissions associated with agriculture (Schneider et al. 2005). There has been extensive research focused on describing and measuring the sources of GHG emissions in agriculture (Smith et al., 2008; Snyder et al., 2009), and there is strong consensus for the need to include all sources of GHG emissions, including the manufacturing of agricultural inputs (Smith et al., 2008; Snyder et al., 2009) in assessing the environmental impact of production. Some studies in recent times have applied this in their system boundary design. Bonesmo et al. (2012) used agricultural statistics for 95 farms in Norway and included upstream emissions in their assessment of carbon footprint. Roches et al. (2010) produced a system to assess environmental impacts at large-spatial extent (albeit coarse spatial resolution) based on FAOSTAT. Smith et al. (2008) and Schneider et al. (2005) used models to estimate GHG emissions from agriculture.

Australia has multiple datasets that describe agricultural production from different angles. The Australian Bureau of Statistics (ABS) has been publishing yearly Agricultural Censuses (combined with coarser Agricultural Surveys) for decades which detail agricultural production at a statistical local area level. The Australian Bureau of Agricultural and Resource Economics and Sciences (ABARES) publishes a time-series of Australian Land Use Maps (ALUM) covering seven years between 1992 and 2005, which categorises $1 \mathrm{~km}^{2}$ pixels into commodity groups including winter cereals, rice, sugar and pastures. Australian state departments of agriculture have been publishing gross margin (GM) handbooks about commodity production for over a decade. These handbooks contain detailed operational data that is considered typical for a certain commodity, location and year. In terms of environmental impacts there are also many sources to draw from. Nemecek et al. (2000) collected data and produced methods for EcoInvent, one of the most widely used life cycle assessment (LCA) datasets which contains hundreds of processes about manufacturing of agricultural inputs. Chen and Baillie (2007) produced a model to estimate fuel and electricity use in Australian on-farm machinery operations.

Linking the aforementioned datasets provides a holistic information platform for production of agricultural commodities. The platform would help assess the GHG emissions and energy-use associated with that production. A link to a Geographical Information System (GIS) will place those emissions and energy requirements in space at a high $\left(1 \mathrm{~km}^{2}\right)$ resolution and national scale, and will allow the analysis of the relationships between GHG emissions and energy use and other variables available geographically such as agricultural yield or profit (Marinoni et al., 2012). The platform will also allow changes in land use to be assessed in term of GHG emissions and energy use.

\section{MATERIALS AND METHODS}

\subsection{System boundaries}

The system boundary describes the sets of operations that are included and modeled, and where data is collected in this project. Our system boundary contains the production of inputs (e.g. chemicals, fodder, seed and fuel), the transport of those inputs, the operation of machinery on farm, and the emissions arising from all of these operations. We excluded production of machinery or infrastructure.

\subsection{Agricultural Practices}

One of the most important sources of data for this study is a collection of over $380 \mathrm{GM}$ datasheets from government departments across all Australian states. The collection (covering 72 commodities across 42 regions) is an expansion of the dataset used in Marinoni et al. (2012). GMs are datasheets generated and provided by agricultural experts from state agencies to inform farmers about the typical farming operations involved in growing a certain crop at each location, typical costs of inputs and operations, typical yield and revenue obtained and how much profit could be generated under different yield conditions. However data from these GMs are difficult to extract due to formatting issues and changing styles. Using Python we designed a GM parser to overcome this problem. It consists of a jargon-savvy module that reads words, interprets them using a pre-built dictionary and categorises them, and 8 guidance modules which navigate through each datasheet and locate data (one module per datasheet style). 


\subsection{Life Cycle Assessment GHG emissions and energy use factors}

In order to estimate the GHG emissions and energy use from an operation listed in the GM dataset we would generally need to access an LCA background system dataset through one of the available LCA software. In our case we use SimaPro (PRé, 2012) and EcoInvent v2 (Nemecek et al., 2000), one of the most widely used LCA datasets. Typically we would need to model every process by hand in SimaPro, run an analysis and note the total GHG emissions and energy use. Our GM dataset has 27,000 records, containing 261 unique operations. We could model 261 operations in SimaPro to obtain GHG emission and energy use factors (i.e. per unit) but the fact that it would have to be done by hand means it is impractical, the chances of errors increase and it is not easily repeatable. Instead we exported the relevant EcoInvent system processes to a matrix. We used Python to read the matrix in Excel format and write it into a database where it can be worked with easily.

The data from EcoInvent is specific to European conditions. If we want to adapt EcoInvent data to Australian systems we need to consider the differences in energy mixes between countries. We collected fertiliser and pesticide import data from the United Nations Commodity Trade Statistics Database (COMTRADE) to find out which countries Australia imported fertilisers and pesticides from and in what proportion between 2000 and 2011 (Figure 1). An analysis of the energy mix of the countries Australia imports from allowed us to calculate an average energy mix for all fertilisers and pesticides used in Australia. Our numbers indicate GHG emissions have been fairly stable during 2000-2011, ranging between 1.05 and $1.14 \mathrm{~kg} \mathrm{CO}_{2}$-e/ $/ \mathrm{kwh}_{\text {of }}$ electricity used for fertiliser manufacturing and between 1 and $0.9 \mathrm{~kg} \mathrm{CO}_{2}$-e/kwh of electricity used for pesticide manufacturing.

EcoInvent v2 lacks data on some machinery and fertiliser processes which we needed to model emissions and energy use from the gross margin dataset. We used EnergyCalc (Chen and Baillie, 2007) to obtain factors for agricultural machinery operations (including irrigation) specific to Australia. We calculated the energy and emissions associated with fertiliser production following Nemecek et al. (2000) and validating the factors with Wood and Cowie (2004). This way we produced a specific emission/energy factor for 97 combinations of Nitrogen, Phosphorus, Potassium and Sulfur (NPKS).

\subsection{Livestock biogenic emissions}

In order to model livestock biogenic emissions consistently with stock numbers used by Marinoni et al. (2012) we used livestock numbers as reported in AgStats 2005/06 and calculated their emissions using the Greenhouse Gas Accounting Framework (Eckart et al., 2008). Herd structures were obtained from ABARES' annual agricultural and grazing industries surveys and validated using available beef and sheep gross margin handbooks, and using Queensland DAFF's Breedcow (DAFF, 2013) herd budgeting software templates for northern beef. Other input parameters such as crude protein intake and dry matter digestibility were obtained from the National Greenhouse Gas Inventory (NGGI) methodology (AGEIS, 2013).

\subsection{Mapping GHG emissions/Energy use and validation}

The GM dataset covers a large number of commodities and growing regions in Australia, but it does not cover every location where every crop is produced. The spatial gaps in the data needed to be filled with the best available data. In order to do this we followed a rule based approach as described in Marinoni et al. (2012). The commodity management practice, GHG emission and energy use data were then aggregated up to commodity categories used in the latest (2005/06) Australian Land Use Map.

In order to test the validity of the gross margin dataset as a whole we performed an analysis over the resulting map that would allow us to compare it to other national scale data. Firstly, we computed the national sum of 
fertiliser applications by product and by NPKS. We compared this sum with data from the Fertiliser Industry Federation of Australia (FIFA) and with fertiliser use statistics from ABS (Table 1).

Table 1. National Fertiliser Use

\begin{tabular}{|c|c|c|c|c|c|}
\hline Source & Mt fertiliser product & Mt N & Mt P & Mt K & Mt S \\
\hline FIFA & $5-6$ & 1 & 0.5 & 0.2 & - \\
\hline GHG map & 6.37 & 1.29 & 0.5 & 0.07 & 0.35 \\
\hline ABS & 6.43 & 0.79 & 0.3 & 0.14 & 0.27 \\
\hline
\end{tabular}

Secondly we downloaded the data published in DE's Agricultural Chemical Usage Database (DE, 2012). The data is presented in online tables in a highly aggregated form and displayed in maps that can be downloaded in .jpeg format. We used GIS analysis to geo-reference the maps published in ACUDB and produce spatial datasets of areas of use per active ingredient (a.i.). Then we mapped the pesticide data from the gross margin dataset to match the areas in ACUDB so that we could compare total pesticide use on equal areas. By comparing the datasets we found the estimates of $\mathrm{kg}$ a.i./ha in the GM dataset were often twice those of ACUDB. In consultation with the custodians of ACUDB we were warned about its limitations. First the data was collected by consultants for marketing purposes so there could be flaws in the data or methodology. Second, farmers may not measure amounts accurately. On the other hand, the estimates in gross margin handbooks may be conservative in nature. Considering these caveats, we argue ACUDB serves as validation for the estimates from the gross margin dataset.

In order to validate our livestock emissions model we compared total livestock numbers and herd structures with those used to produce NGGI 2006 estimates (Table 2). Pigs and other livestock were not included in our model.

Table 2. Comparison of herd sizes and structures between GHG map and NGGI 2006

\begin{tabular}{|c|c|c|c|c|c|c|c|c|}
\hline \multicolumn{3}{|c|}{ Beef Cattle } & \multicolumn{3}{|c|}{ Dairy Cattle } & \multicolumn{3}{|c|}{ Sheep } \\
\hline & NGGI 06 & GHG map & & NGGI 06 & GHG map & & NGGI 06 & GHG map \\
\hline Million heads & 24.31 & 25.59 & Million heads & 2.79 & 2.78 & Million heads & 91.03 & 90.94 \\
\hline Bulls >1 & $2 \%$ & $1 \%$ & Milking cows & $67 \%$ & $61 \%$ & Rams & $1 \%$ & $1 \%$ \\
\hline Bulls <1 & $1 \%$ & $0 \%$ & Heifers $>1$ & $21 \%$ & $19 \%$ & Wethers & $17 \%$ & $2 \%$ \\
\hline Steers $<1$ & $12 \%$ & $15 \%$ & Heifers <1 & $11 \%$ & $19 \%$ & Ewes & $72 \%$ & $58 \%$ \\
\hline Steers $>1$ & $20 \%$ & $10 \%$ & Dairy Bulls >1 & $1 \%$ & $1 \%$ & Lambs \& Hoggets & $27 \%$ & $40 \%$ \\
\hline Cows 1 to 2 & $15 \%$ & $18 \%$ & Dairy Bulls <1 & $0 \%$ & $0 \%$ & - & - & - \\
\hline Cows $>2$ & $40 \%$ & $42 \%$ & House Cows & $0 \%$ & $0 \%$ & - & - & - \\
\hline Cows $<1$ & $11 \%$ & $15 \%$ & - & - & - & - & - & - \\
\hline
\end{tabular}

\section{RESULTS}

Our analysis shows 95.8 $\mathrm{Mt} \mathrm{CO}_{2}$-e were emitted and 75.7 GWh of energy used in 2005/06 as a result of agricultural production in Australia. Emissions from sources that were categorised as non-agricultural (e.g. industrial processes or energy use) in NGGI 2006 amounted to $28.2 \mathrm{Mt} \mathrm{CO}_{2}$-e (29.4\%) The highest of these sources are fertiliser and pesticide manufacturing (Figure 2). However the GHG profile varies between commodity groups (Figure 5).

Livestock production was responsible for $70 \%$ of total emissions followed by winter cereal production (19\%) (Figure 3). However livestock is the lowest emitter per hectare (Figure 3) because it occupies the largest amount of land. Our estimate of total livestock emissions (60.6 Mt $\mathrm{CO}_{2}$-e) is $10 \mathrm{Mt} \mathrm{CO}_{2}$-e less than the NGGI 2006 estimate (15\% difference). An analysis of on-farm/off-farm emissions shows that $21 \%$ of total GHG emissions and $62 \%$ of total energy use was associated with off-farm processes (i.e.

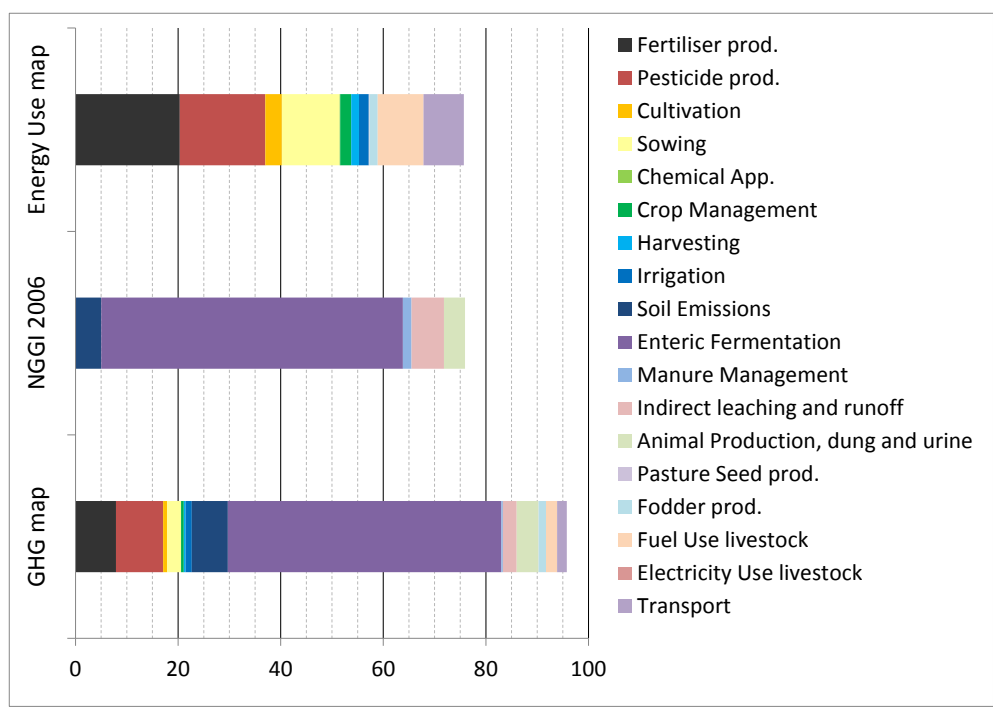

Figure 2. GHG emissions ( $\left.\mathrm{Mt} \mathrm{CO}_{2}-\mathrm{e}\right)$ and energy use (GWh), Australia 
fertiliser/pesticide production and transport). On-farm emissions include the burning of fuel in tractors, fuel/electricity use for irrigation and electricity use in milk production (including fuel and electricity production).

On average broadacre crops emitted $2 \mathrm{~kg} \mathrm{CO} 2$-e/\$ profit and used $0.04 \mathrm{kWh} / \$$, livestock 2.8 $\mathrm{kg} \mathrm{CO}$-e/\$ and $0.3 \mathrm{kWh} / \$$, and horticultural crops $0.4 \mathrm{~kg} \mathrm{CO} 2^{-}$ $\mathrm{e} / \$$ and $0.01 \mathrm{kWh} / \$$ (Figure 4).

A spatial analysis of total emissions by area suggests that about $90 \%$ of GHG are emitted in $30 \%$ of the total agricultural area. The temperate seasonally dry slopes and plains AgroEcological region (AER) contains just over $40 \%$ of emissions, followed by the subhumid, sub-tropical slopes and plains AER at $12 \%$. This can be identified in Figure 6 as approximately the areas colourcoded light blue or higher.

\section{DISCUSSION}

The system we have produced allows us to estimate the GHG emissions and energy use patterns of Australian agriculture from a lifecycle perspective at different scales. This will allow us to explore the implications on regional and national emissions of different mitigation strategies, land use changes, or policy scenarios. Without a complete assessment of on-farm and upstream emissions and energy use the performance of mitigation strategies becomes harder to compare. For example one may increase fertilisation rate in order to produce more plant residue and increase soil carbon levels, but in some cases the carbon sink produced may be outweighed by the GHG emitted during fertiliser manufacturing.

There are multiple options available to reduce GHG emissions. Reducing fertiliser and pesticide use would have significant impact but it could come at the cost of yield. Precision agriculture could serve to optimize NPKS input for yield and

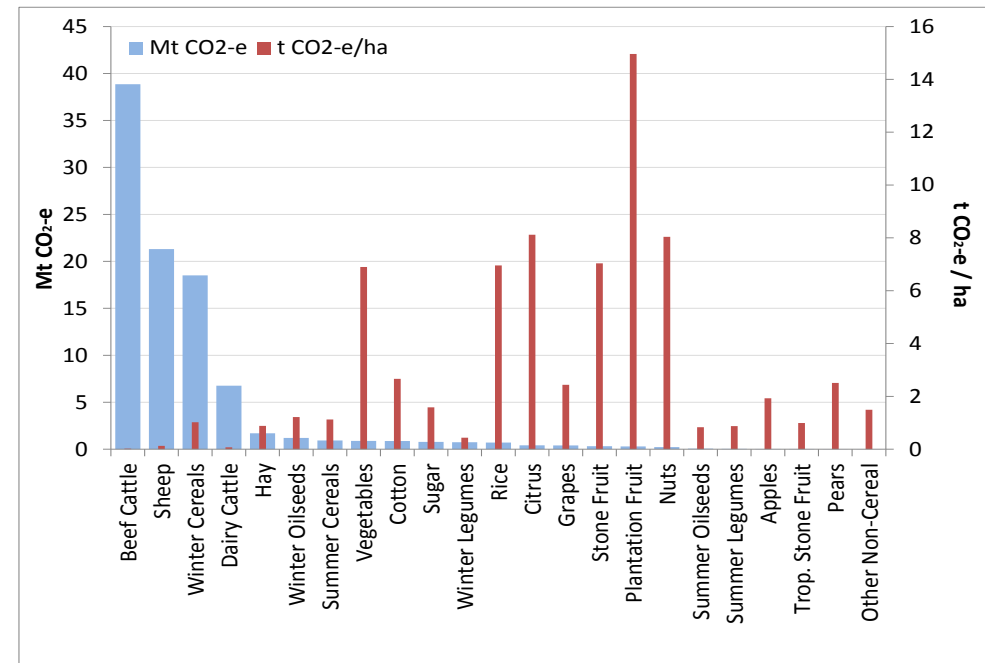

Figure 3. GHG and GHG/hectare per commodity group

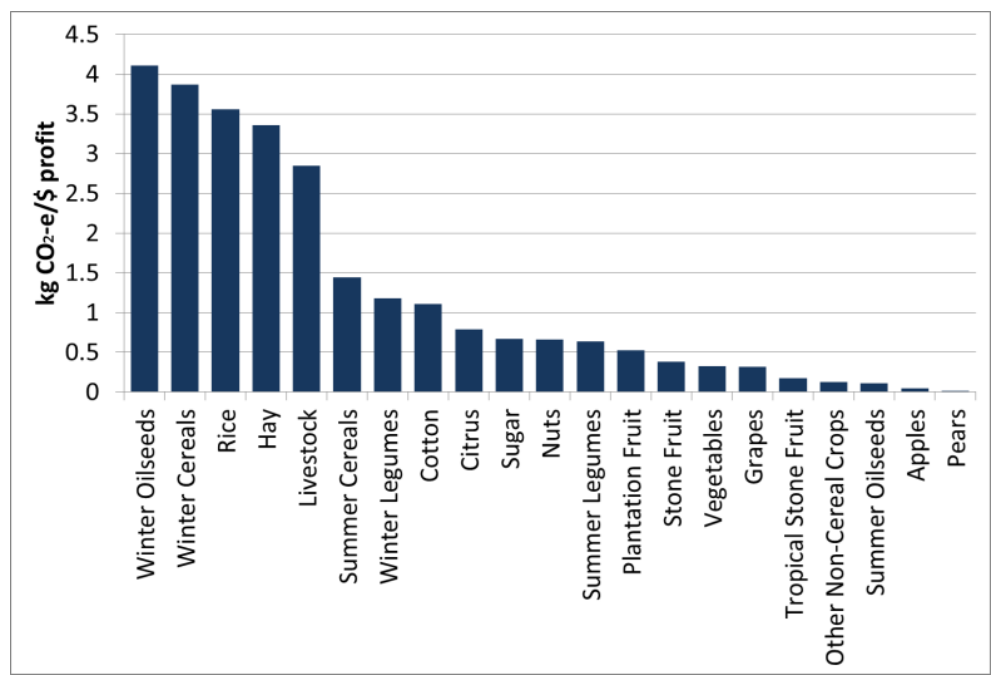

Figure 4. GHG emissions per \$ profit 2005/06

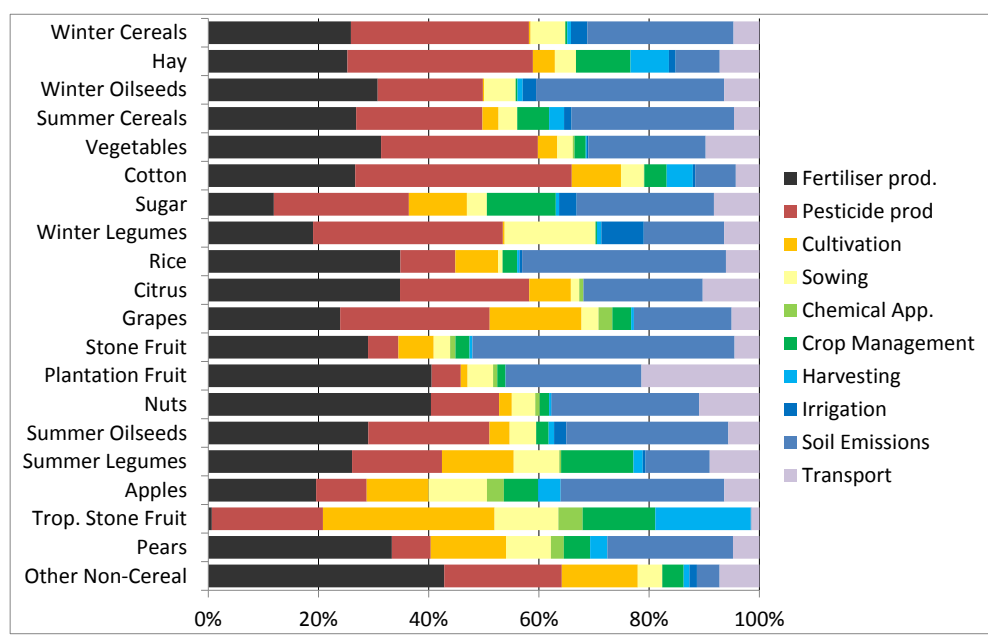

Figure 5. GHG emission profile per commodity group 


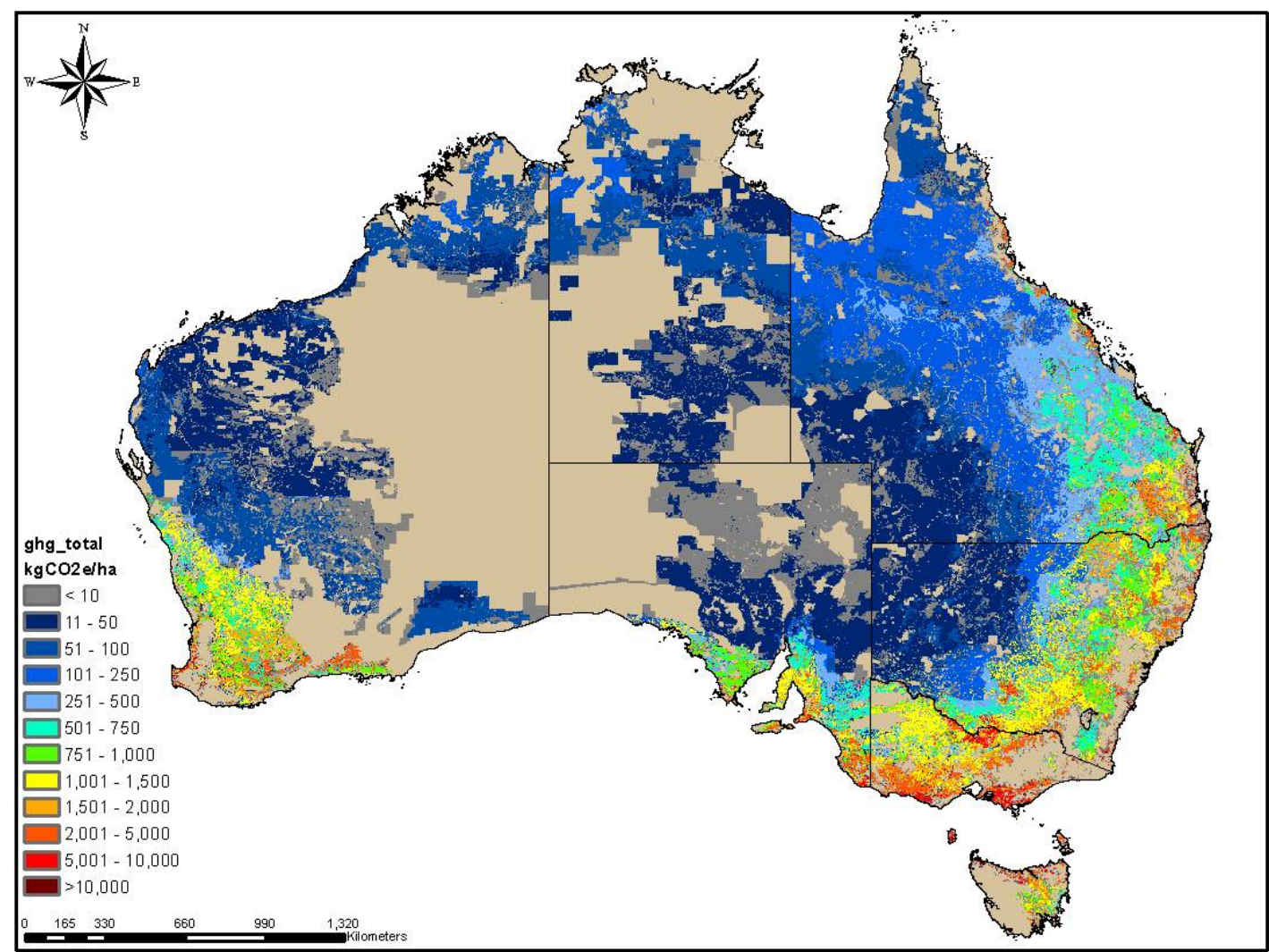

Figure 6. Map of GHG emissions

reduce agricultural soil emissions (Grassini and Cassman, 2012). Production of biofuels from corn stover and sugarcane bagasse is an option for utilizing biomass for energy that does not compete with food production. An analysis of agricultural production for these two types of biomass in 2005/06 based on Somerville et al. (2010) shows 1.71 GL of ethanol could have been produced. Assuming 1 litre of ethanol can displace a maximum of 0.83 litre of gasoline (AFDC, 2013), an emission factor of $3.08 \mathrm{~kg} \mathrm{CO}_{2}$-e/litre gasoline (DIICSRT, 2013) (including emissions from manufacturing), ethanol from corn stover and sugarcane bagasse could have avoided 4.38 $\mathrm{Mt} \mathrm{CO}_{2}$-e emissions (4.56\% of total agricultural emissions as per our system).

Agricultural studies analysing the emissions from fertiliser manufacturing use emission factors between 3-4.5 $\mathrm{kg} \mathrm{CO}_{2}$-e/kg N (Snyder et al., 2009; Bonesmo et al., 2012). Our findings show GHG intensity varies between commodity groups (Table 3). For example apple production seems to involve fertilisers that are less GHG intensive than the ones used in winter cereal production. For this reason we suggest it is better to express emission factors as $\mathrm{kg} \mathrm{CO}$-e/ $\mathrm{kg}$ NPKS and be specific to commodity groups than to use a constant factor based solely on $\mathrm{N}$ input across different commodity groups (unless case specific fertilization rates and fertiliser-specific emission factors are used). However if expressing emission factors per $\mathrm{kg} \mathrm{N}$ is imperative we suggest an emission factor of 5.8-6 $\mathrm{kg} \mathrm{CO}_{2}-\mathrm{e} / \mathrm{kg} \mathrm{N}$ would be more appropriate for broadacre crops (except legumes) and 4-10 $\mathrm{kg} \mathrm{CO}_{2}-\mathrm{e} / \mathrm{kg} \mathrm{N}$ for horticultural crops.

Table 3. Suggested GHG emission factors for fertilisers

\begin{tabular}{|c|c|c|c|}
\hline Commodity Category & median kg CO2-e / kg NPKS & Commodity Category & median kg CO2-e / kg NPKS \\
\hline Apples & 2.80 & Summer Cereals & 4.68 \\
\hline Citrus & 3.54 & Summer Legumes & 2.89 \\
\hline Cotton & 4.85 & Summer Oilseeds & 5.08 \\
\hline Grapes & 5.74 & Tropical Stone Fruit & 2.52 \\
\hline Hay & 3.14 & Vegetables & 3.91 \\
\hline Plantation Fruit & 2.47 & Winter Cereals & 4.68 \\
\hline Rice & 5.04 & Winter Legumes & 3.43 \\
\hline Stone Fruit & 3.49 & Winter Oilseeds & 4.02 \\
\hline Sugar & 1.19 & - & - \\
\hline
\end{tabular}

Table 1 in Smith et al. (2008) provides a qualitative assessment of GHG mitigation potential from management practices and a measure of confidence based on the literature. Our results provide quantities that can complement this assessment and increase reliability of results. Janzen et al. (2006) reported emissions of 
11.6 $\mathrm{Mt} \mathrm{CO}_{2}$-e from energy use on farm and $12 \mathrm{Mt} \mathrm{CO}_{2}$-e from production of inputs, machinery, buildings

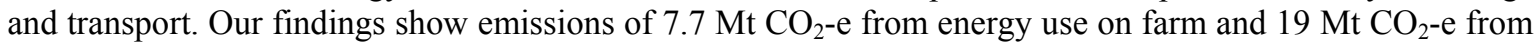
inputs production and transport. Both estimates are comparable in magnitude despite the different contexts and system boundaries

\section{CONCLUSION}

This study provided a holistic picture of agricultural emissions for the whole of Australia at $1 \mathrm{~km}^{2}$ resolution. Our system will help identify new opportunities for emission reduction and assess their effect. The study also provided new base data and GHG emission factors for use by the Australian LCA community. Further work should focus on estimating the uncertainty in our base data and its propagation throughout the system.

There is significant scope for biofuel production to offset agricultural GHG emissions. We have estimated $4.56 \%$ reduction in agricultural cradle-to-gate emissions could have been possible through ethanol production from corn stover and bagasse alone. Further work could focus on the how ethanol production could reduce the footprint of agricultural commodities and any possible food-security implications.

\section{REFERENCES}

Alternative Fuels Data Centre, 2013, E85 http://www.afdc.energy.gov/fuels/ethanol_e85.html

Australian Greenhouse Emissions Information System (AGEIS), 2013 http://ageis.climatechange.gov.au/

Bonesmo, Helge, Arne Oddvar Skjelvåg, H Henry Janzen, Ove Klakegg, and Ole Einar Tveito. 2012.

"Greenhouse gas emission intensities and economic efficiency in crop production: A systems analysis of 95 farms." Agricultural Systems 110,142-151.

Chen, Guangnan, and Craig Baillie. 2007. Development of EnergyCalc-A tool to assess cotton on-farm energy uses. University of Southern Queensland NCEA Publication.

Department of Agriculture, Fisheries and Forestry (Queensland), 2012, Breedcow and Dynama software http://www.daff.qld.gov.au/business-trade/business-and-trade-services/breedcow-and-dynama-software

Department of the Environment, 2012, Agricultural Chemical Usage Database http://www.environment.gov.au/settlements/chemicals/agriculture/index.html

Department of Industry, Innovation, Climate Change, Science, Research and Tertiary Education 2013, National Greenhouse Accounts Factors, Australian Government.

Eckard, Richard, Hegarty, Roger and Thomas, Geoff (2008) Greenhouse Accounting Framework. Project no: UM10778 http://www.greenhouse.unimelb.edu.au/Tools.htm

Grassini, Patricio, and Kenneth G Cassman. 2012. "High-yield maize with large net energy yield and small global warming intensity." Proceedings of the National Academy of Sciences 109 (4),1074-1079.

Janzen, HH, DA Angers, M Boehm, M Bolinder, RL Desjardins, J Dyer, BH Ellert, et al. 2006. “A proposed approach to estimate and reduce net greenhouse gas emissions from whole farms." Canadian journal of soil science 86 (3),401-418.

Marinoni, Oswald, Javi Navarro Garcia, Steve Marvanek, Di Prestwidge, David Clifford, and LA Laredo. 2012. "Development of a system to produce maps of agricultural profit on a continental scale: An example for Australia." Agricultural Systems 105 (1),33-45.

Nemecek, Thomas, A Heil, O Huguenin, S Meier, S Erzinger, S Blaser, D Dux, and A Zimmermann. 2000. "Life cycle inventories of agricultural production systems." Final report ecoinvent 15.

PRé consultants, 2012, SimaPro v7.3 http://www.pre-sustainability.com/

Roches, Anne, Thomas Nemecek, Gérard Gaillard, Katharina Plassmann, Sarah Sim, Henry King, and Llorenç Milà i Canals. 2010. "MEXALCA: a modular method for the extrapolation of crop LCA." The International Journal of Life Cycle Assessment 15 (8),842-854.

Schneider, Uwe A, Bruce A McCarl, and others. 2005. "Implications of a carbon-based energy tax for US agriculture." Agricultural and Resource Economics Review 34 (2),265.

Smith, Pete, Daniel Martino, Zucong Cai, Daniel Gwary, Henry Janzen, Pushpam Kumar, Bruce McCarl, et al. 2008. "Greenhouse gas mitigation in agriculture." Philosophical Transactions of the Royal Society B: Biological Sciences 363 (1492),789-813.

Snyder, CS, TW Bruulsema, TL Jensen, and PE Fixen. 2009. "Review of greenhouse gas emissions from crop production systems and fertilizer management effects." Agriculture, Ecosystems \& Environment 133 (3), 247-266.

Somerville, Chris, Heather Youngs, Caroline Taylor, Sarah C Davis, Stephen P Long, and others. 2010. "Feedstocks for lignocellulosic biofuels." Science(Washington) 329 (5993),790-792.

Wood, Sam, and Annette Cowie. 2004. A review of greenhouse gas emission factors for fertiliser production. In IEA bioenergy task, 38:20. 